\title{
Uma proposta de operação dos princípios linguísticos saussurianos nos estudos de gênero
}

Adriana Tulio Baggio

\begin{abstract}
Resumo
Este artigo propõe um modelo para os estudos de gênero baseado nos princípios linguísticos de F. de Saussure. Assume-se que as relações estabelecidas por Saussure entre o sistema da lingua e outros sistemas semiológicos, como o gênero, autorizam a projeção neste sistema dos princípios daquele. O modelo concentra-se nos conceitos de lingua e fala, significante e significado, arbitrariedade e motivação relativa do signo, e valor. Procura mostrar que a noção de língua como um sistema de relações - do signo como algo convencionado e do valor como constituidor da identidade alinha-se à concepção de gênero como construção e como discurso. Desta forma, a abordagem rejeita a ideia de uma origem natural das classificações e normas de gênero, assim como Saussure rejeita o mesmo para a lingua. Para tratar das regras que organizam as relações de gênero, projetam-se nele os conceitos de gramática normativa e gramática descritiva da língua. Enquanto a primeira determina e impõe as relações e as identidades com base em uma matriz heterossexual compulsória, a segunda pode cumprir o papel de desvelar aquilo que efetivamente emerge do sistema. Buscase mostrar que o modelo pode ser produtivo para dar conta das identidades gênero-divergentes nos casos em que é preferível evitar a abordagem das denominações e classificações dessas identidades. Sugere-se também que o modelo possa ser especialmente útil para a adoção de um viés de gênero na pesquisa científica, pois sua base linguística facilita a transversalidade às diversas áreas.
\end{abstract}

Palavras-chave: Saussure. Estudos de gênero. Gramática de gênero. Língua e fala. Teoria do valor.

a Pós-doutoranda do PPG em Tecnologia e Sociedade da UTFPR. Pesquisadora do CPS - Centro de Pesquisas Sociossemióticas da PUC-SP; E-mail: atbaggio@gmail.com. 


\section{Introdução}

O termo "gênero" no título do artigo refere-se não aos gêneros textuais, nem à flexão responsável pela variação dos substantivos, mas ao "conjunto de propriedades atribuídas social e culturalmente em relação ao sexo dos indivíduos" (GÊNERO, 2013). Neste sentido, o gênero constitui uma categoria de diferenciação social formada por dois termos, masculino e feminino, comumente homologada à categoria de diferenciação biológica macho e fêmea.

A antropóloga francesa Nicole-Claude Mathieu aponta que as sociedades humanas sobrevalorizam essa diferenciação biológica ao atribuir aos dois sexos funções divididas, separadas e hierarquizadas que extrapolam o âmbito individual e permeiam o corpo social como um todo. Diz ainda que as sociedades aplicam a essas diferenciações "[...] uma 'gramática': um gênero (um tipo) 'feminino' é culturalmente imposto à fêmea para que se torne uma mulher social, e um gênero 'masculino' ao macho, para que se torne um homem social" (MATHIEU, 2009, p. 223).

Destaco nesta fala o uso de "gramática" para se referir às normas que regem os papéis, funções, direitos e deveres sociais relativos às coisas da ordem do masculino e àquelas da ordem do feminino. É um termo comumente associado às discussões linguísticas. No entanto, mesmo em textos desta natureza, o conceito de gramática acaba sendo dilatado para outras áreas. $\mathrm{O}$ próprio Ferdinand de Saussure faz isso no Curso de linguística geral. Para explicar o sentido de gramática enquanto descrição de um estado de língua (a linguística sincrônica), faz associação com uma "gramática do xadrez" ou uma "gramática da bolsa". A gramática então "[...] trata de um objeto complexo e sistemático, que põe em jogo valores coexistentes" (SAUSSURE, 2012, p. 183).

Penso que a convocação do conceito de gramática para explicar as articulações de um fato social como o gênero e, de outro lado, uma definição de gramática que engloba outros sistemas além da língua, estabelece uma relação entre gênero e língua. Partindo desta premissa, seria possível entender as relações de gênero a partir de princípios da ciência linguística e, mais especificamente, a partir dos elementos da teoria saussuriana? 
É uma questão que pode parecer repetitiva, pois muitos estudos de gênero - inclusive os de Judith Butler, autora que será discutida no artigo - têm uma base estruturalista cujos princípios são descendentes dos pressupostos do linguista genebrino, ou focam especificamente na linguagem. No entanto, diferentemente destas outras abordagens, pretendo levar a cabo uma associação mais direta entre o gênero e os princípios de Saussure, testando a ideia de uma "línguagênero" a partir da operação de alguns desses princípios.

O objetivo é propor uma grade de leitura para o entendimento do gênero tanto em seu aspecto teórico quanto político, especialmente para pesquisadoras e pesquisadores que, como a psicanalista Leticia Lanz, discutem as dificuldades envolvidas nas definições e classificações das identidades gênero-divergentes. Para Lanz, esses processos frequentemente “[...] têm servido muito mais como mecanismos de opressão do que como estratégias libertárias [...]" (LANZ, 2015, p. 365).

A proposta de exercício de uma "língua-gênero" talvez possa ser melhor compreendida se for abordada a partir do conceito de metalinguagem, conforme tratado por Algirdas Julien Greimas (2000) em L'actualité du saussurisme, artigo publicado originalmente em 1956. Greimas propõe que a língua, permanecendo o que ela é em relação a certos conjuntos de significação autônomos, como a mitologia ou a literatura - ou seja, permanecendo um sistema de signos -, é utilizada ao mesmo tempo como instrumento e serve para construir "ordens de pensamento" mediatizadas, que são as metalinguagens (cujo mérito da aplicação na literatura Greimas credita a Roland Barthes). Essas metalinguagens se servem dos signos linguísticos para desenvolver suas formas autônomas.

1 Tradução minha para: "Ainsi, selon la suggestion féconde de Hjelmslev, en partant d'un ensemble signifiant nettement structuré: littérature, langue populaire, mythologie, on est autorisé à construire un système sémiologique dont les structures, dégagées par l'analyse, comporteraient une signification globale autonome."
Desta forma, segundo a proveitosa sugestão de Hjelmslev, partindo de um conjunto significante claramente estruturado: literatura, língua popular, mitologia, estamos autorizados a construir um sistema semiológico em que as estruturas, depuradas por análise, comportariam uma significação global autônoma. ${ }^{1}$ (GREIMAS, 2000, p. 376)

O que desenvolvo a seguir, portanto, são associações entre gênero e língua que mostram a construção de um sistema com significação global autônoma, como é o gênero. Feito o esclarecimento, deixo de lado o termo metalinguagem e permaneço com a expressão "língua-gênero". 
Outra delimitação importante diz respeito ao uso do Curso de linguística geral como fonte destes princípios. São muitas as críticas feitas à validade do seu conteúdo, à eventual superficialidade de alguns conceitos ou ao equívoco na apresentação de outros, como mostram Simon Bouquet (2009) e outros revisionistas a partir da análise de notas e manuscritos do próprio Saussure encontrados/trabalhados posteriormente à edição do Curso. Penso, no entanto, que os conceitos foram validados pelo próprio uso que deles foi feito para erigir disciplinas sólidas como a teoria da linguagem de Louis Hjelmslev, a antropologia estrutural de Claude Lévi-Strauss e a semiótica discursiva de Greimas, para citar apenas algumas.

Se, como dizem José Luiz Fiorin, Valdir do Nascimento Flores e Leci Borges Barbisan, estudar Saussure implica uma tomada ética de posição em relação às diversas fontes do pensamento saussuriano, a que adoto neste trabalho é a de "[...] ignorar o 'verdadeiro' Saussure e restringir-[me] ao estudo apenas do Curso" (TRABANT, 2005 apud FIORIN; FLORES; BARBISAN, 2013, p. 16).

Estes três linguistas também expressam um ponto de vista sobre a relevância da obra de Saussure que considero especialmente pertinente aos estudos contemporâneos de gênero:

Num momento em que reaparecem, com força total, as teses biológicas para explicar os fatos humanos, num esvaziamento de sua dimensão social e cultural, Saussure é mais atual do que nunca. É necessário na resistência à desumanização das chamadas 'ciências do homem'. (FIORIN; FLORES; BARBISAN, 2013, p. 9)

Antes de tratar propriamente da operação dos princípios de Saussure na proposta de uma visão do gênero como língua, discuto mais detalhadamente algumas concepções acerca do gênero e sua gramática. Tais concepções serão depois associadas aos princípios.

\section{A gramática do gênero}

Para Saussure - como visto logo antes -, a gramática trata de um objeto complexo e sistemático que põe em jogo valores coexistentes. Complexidade, sistema, valores e coexistência: 
todas essas ideias estão no conceito de gênero apresentado por Maria Izilda Santos de Matos:

Por sua característica basicamente relacional, a categoria gênero procura destacar que a construção do feminino e masculino define-se um em função do outro, uma vez que se constituíram social, cultural e historicamente em um tempo, espaço e cultura determinados. Não se deve esquecer, ainda, que as relações de gênero são um elemento constitutivo das relações sociais baseadas nas diferenças hierárquicas [valores] que distinguem os gêneros, e são, portanto, uma forma primária de relações significantes de poder. (MATOS, 2017, p. 46, grifos meus)

As construções do masculino e do feminino e das suas relações colocam em jogo aspectos de identidade e de sexualidade distribuídos em três dimensões - ou categorias ${ }^{2}$ - que se articulam na constituição de uma norma que governa boa parte da nossa sociedade. São elas: o sexo, a identidade de gênero e a expressão de gênero. Cada uma dessas categorias é estruturada em dois polos opostos que, dentro de uma noção normativa, seriam as únicas opções possíveis. No sexo estão as classificações macho e fêmea; na identidade, as classificações homem e mulher; na expressão, as classificações masculino e feminino. Estas classificações atuam exclusivamente na orientação heterossexual e rejeitam a possibilidade da homossexualidade e de qualquer outra orientação sexual.

Justamente por isso, essa noção normativa é vista por Judith Butler como uma grade de inteligibilidade cultural chamada de matriz heterossexual. A matriz presume, dentro de uma concepção de estabilidade das categorias, que os corpos devem ter uma coerência entre sexo, identidade e expressão de gênero, coerência esta ancorada na prática compulsória da heterossexualidade (BUTLER, 1993, p. 216). Neste entendimento, uma pessoa classificada como macho na categoria sexo deverá manifestar marcas e adotar práticas que o enquadrem nas classificações correspondentes a esta posição nas outras categorias, que são homem (identidade de

2 Dentro de uma p e r s p e c $t$ i v a saussuriana, entendo como categoria tanto o gênero quanto as dimensões que compõem essa categoria. gênero) e masculino (expressão de gênero). $\mathrm{O}$ mesmo ocorre, obviamente, para a pessoa fêmea, que deve identificar-se com a classificação mulher e expressar marcas do feminino.

A justificativa para a imposição desse regime de coerência dos corpos e o entendimento da heterossexualidade como a 
forma "normal" de relacionamento afetivo-sexual estaria baseada em sua pretensa naturalidade - as coisas são assim porque nós nascemos assim. Diante disso, outras combinações entre os elementos das categorias são consideradas antinaturais e, portanto, recusadas e não raramente criminalizadas. Como não é difícil de compreender, a imposição de um determinado regime e a interdição de outros têm efeitos bastante importantes na vida social e política, como fica claro na explicação de Matos no início desta seção.

A perspectiva de gênero adotada em diversos campos do conhecimento desconstrói essa concepção. Judith Butler busca na filosofia, na linguística e na psicanálise as razões para mostrar que não existe um gênero que seja natural, ou real, ou original. $\mathrm{O}$ gênero é algo feito, é construído ${ }^{3}$, ainda que não se possa identificar "quem" o fez. Nesse processo, "[...] certas configurações culturais do gênero assumem o lugar do 'real' e consolidam e incrementam sua hegemonia por meio de uma autonaturalização apta e bem-sucedida" (BUTLER, 2003, p. 58). Voltarei a esse ponto mais adiante.

As normas que regem as articulações entre sexo, identidade e expressão de gênero e orientação sexual são, portanto, construções; não estão relacionadas a alguma lei da natureza ou à essência do ser humano. No entanto, são úteis para a manutenção de certas formas de organização da vida social - como a divisão sexual do trabalho, por exemplo -, pois determinam papéis, direitos e tipos de relacionamento que cada pessoa pode realizar ou almejar. Entendendo tais normas como uma gramática, vale para o gênero aquilo que Saussure (2012, p. 185) diz sobre a língua: “[...] as divisões tradicionais da Gramática podem ter sua utilidade prática, mas não correspondem a distinções naturais e não estão unidas por nenhum vínculo lógico".

A gramática do gênero divide e classifica as pessoas e as coisas do mundo em masculinas ou femininas, investe de valor estes elementos e coloca-os em jogo. Mas assim como a gramática da língua em si não é ruim, talvez não o seja a gramática de gênero. É a sua operação que gera as opressões e as desigualdades. Uma das operações problemáticas, reforço, é a equivocada concepção de que as categorias e classificações estão de alguma forma relacionadas à ordem natural das coisas. Outra é considerar que existem apenas os elementos 
opostos de cada categoria e não posições intermediárias e/ou fluidas entre os polos, bem como diferentes combinações entre as classificações de cada categoria. E a terceira é a valoração que se atribui a cada classificação. Por exemplo: as sociedades ocidentais caracterizam-se ainda hoje, de forma geral, por uma recorrente disforia do feminino e suas expressões. Ao usar o termo "feminino" e não "mulher", busco destacar que essa valoração opera não apenas em mulheres (e também não apenas em pessoas). Raewyn Connell (1997, p. 41) mostra que, de acordo com o ponto de vista de alguns teóricos homossexuais, a ferocidade dos ataques homofóbicos a homens gays deve-se às marcas de feminilidade associadas a essa orientação.

Para aprofundar a ideia de que a gramática em si não é o problema, penso em duas abordagens da gramática da língua, apresentadas por Carlos Franchi (2006), que acredito serem produtivas em sua associação à gramática do gênero. A primeira delas é a que diferencia a "gramática interna" da "gramática" enquanto construção teórica. A gramática interna "[...] é um sistema de princípios e regras que correspondem ao próprio saber linguístico do falante: ele se constrói na atividade linguística e na atividade linguística se desenvolve" (FRANCHI, 2006, p. 31). Existiria, portanto, um "saber" de gênero que se constrói na observação e na vivência das operações de gênero que articulam o mundo, e que a pessoa associa com seus sentimentos, suas sensações, sua forma de viver e pensar este mundo. Neste sentido, assim como na concepção da gramática da língua, existem muitas "variedades" possíveis, todas perfeitamente coerentes e corretas na articulação dos diferentes elementos da língua-gênero.

A gramática teórica, por sua vez, trata de "[...] construir um sistema de noções e uma metalinguagem que permitam falar da linguagem e descrever (ou explicar) os seus princípios de construção" (FRANCHI, 2006, p. 31). As quatro dimensões operadas nos estudos de gênero - sexo, identidade de gênero, expressão de gênero e orientação sexual - são um exemplo do que poderia constituir essa gramática teórica do gênero. Ou seja, em algum momento decidiu-se nomear, categorizar e classificar o sistema que cada indivíduo ou grupo opera internamente. E, neste ponto, entra em cena a segunda abordagem, a que distingue a gramática normativa da descritiva. 
Uma ideia de gramática descritiva ancora-se na própria noção de Saussure, como já vimos, de que a gramática descreve um estado de língua. Na definição de Franchi, uma gramática descritiva "[...] é um sistema de noções mediante as quais se descrevem os fatos de uma língua, permitindo associar a cada expressão dessa língua uma descrição estrutural e estabelecer suas regras de uso, de modo a separar o que é gramatical do que não é" (FRANCHI, 2006, p. 22). A utilidade de um modelo de gramática de gênero para os estudos de gênero consistiria nessa descrição dos fatos de gênero em suas mais diferentes variedades, buscando entender suas estruturas e suas regras de uso. Note-se que "estabelecer regras" não significa dizer como cada "variedade" de expressão de gênero deve agir, e sim apontar quais as regras já operadas por essa variedade. Não se trata de ensinar, mas de observar e descrever.

Quanto à última parte da definição, a separação entre o que é ou não gramatical, ela parece levar a uma delimitação do que seria "certo" ou "errado" em termos de gênero. Na verdade, a "agramaticalidade" tem a ver com o que efetivamente é impossível em termos gramaticais em cada variedade ${ }^{4}$, e não com o que a norma impõe. Exercitando esse conceito na ideia de uma gramática de gênero, penso que a coerência absoluta entre sexo, identidade de gênero e expressão de gênero é o que se pode considerar como "agramatical". Já que a nossa cultura divide e classifica as emoções, os gestos, os tons de voz, as organizações corporais e muitos outros aspectos da nossa

${ }^{4}$ A sinalização do plural costuma ser um exemplo emblemático para mostrar que mesmo as variedades consideradas menos prestigiosas-pois destoam da norma culta - também têm suas regras, não se trata de um vale-tudo. Carlos Franchi mostra que "[...] em um sintagma nominal complexo, a modalidade coloquial se contenta em assinalar morfologicamente a pluralidade em um só de seus constituintes [mas] não é qualquer constituinte que pode receber a marca de pluralidade; esta incide, praticamente sem exceções, sobre o primeiro determinante compatível com essa marca" (FRANCHI, 2006, p. 28-29). identidade e aparência como "masculinos" ou "femininos", vejo como impossível que alguém seja 100\% fêmea, mulher e feminina ou $100 \%$ macho, homem e masculino. E, no entanto, é a expectativa de tal alinhamento que, paradoxalmente, está no horizonte da gramática que se opõe à descritiva, a gramática normativa do gênero.

Na língua, a gramática normativa consiste no “[...] conjunto sistemático de normas para bem falar e escrever, estabelecidas pelos especialistas, com base no uso da língua consagrado pelos bons escritores" (FRANCHI, 2006, p. 16, grifos do autor). O conceito de matriz heterossexual de Butler é um exemplo de operação da gramática normativa do gênero. As normas que operam de acordo com essa matriz foram construídas e impostas, como já vimos. Sua permanência acontece também pela reiteração da representação dos 
modelos da matriz tanto nas práticas de vida das pessoas quanto nos discursos socioculturais, ignorando ou negando as outras "variedades". Desta forma, tem-se a ideia de que tais modelos são os corretos, os normais e os naturais, justamente por sua consagração.

Muitas distorções em resultados de pesquisas científicas devem-se ao fato de que se opera tacitamente dentro de uma gramática normativa de gênero. Lola Schiebinger (2014), por exemplo, trata dos "efeitos nefastos" dessa normatividade nas ciências biológicas e biomédicas. Não se considera o viés de gênero porque é algo dado, natural, sem interferência. Adotar uma perspectiva descritiva, que leve em conta as muitas "variedades", é fundamental para evitar essas distorções, cujas consequências são bastante graves.

Ainda sobre uma visão normativa da gramática: tal perspectiva está intimamente relacionada à constituição dos estados-nação a partir do princípio do nacionalismo, como mostra Eric Hobsbawm (1990). O nacionalismo moderno exige uma identificação e um comprometimento dos seus integrantes que supera qualquer outra obrigação ou identidade preexistente. E o estabelecimento e imposição de uma língua padrão compulsória, por meio de uma gramática normativa (que deve ser adotada por todos e que apaga as variedades não desejáveis), teve importante papel na formação dos estadosnação do século XIX e nos nacionalismos totalitários.

Interessante notar que é da mesma época a consolidação do que veio a ser chamado de ideologia das esferas separadas: uma rígida divisão das pessoas, dos papéis sociais a assumir e dos espaços que poderiam ocupar a partir do seu sexo e das características a ele (pretensamente) inerentes. A adoção, por muitas nações, de uma gramática normativa da língua, para fins políticos e ideológicos, foi acompanhada pela adoção de uma gramática normativa do gênero, baseada na matriz heterossexual, com os mesmos objetivos e prejuízo das liberdades individuais. E apesar de todos os esforços para uma outra visão, é esta abordagem normativa que predomina ainda hoje tanto em um quanto em outro sistema.

Realizado o exercício de associar as noções de gramática ao sistema de gênero, passo à proposta de entender o gênero segundo as concepções saussurianas de língua. 


\section{Entendendo gênero como língua}

Penso que a proposição de uma gramática do gênero baseada nas noções da gramática da língua não apresenta muitos desafios, pois é comum que o sentido de gramática extrapole os domínios da linguística. O mesmo talvez não aconteça com a associação entre gênero e língua e o decorrente exercício de proposição de uma língua-gênero, a não ser que se aceitem as relações de pertencimento propostas por Saussure: a língua como parte da linguagem, que por sua vez integra a semiologia.

A semiologia estuda os signos na vida social e as leis que os regem, mas não apenas os signos linguísticos. Os signos que marcam o gênero - roupas, expressões corporais, tom de voz, cores, raças de cachorro, profissões etc. - podem ser estudados pela semiologia, como de fato o são há bastante tempo. Mas apesar de a língua ser apenas uma parte deste sistema mais amplo e diversificado, para Saussure ela é o principal deles e são as suas leis que regem esse sistema. Desta forma, toma-se a língua "[...] como norma de todas as outras manifestações da linguagem" (SAUSSURE, 2012, p. 41), e considera-se que “[...] o problema linguístico é, antes de tudo, semiológico, e todos os nossos desenvolvimentos emprestam significação a esse fato importante" (SAUSSURE, 2012, p. 49).

Os princípios de Saussure aqui operados na proposição dessa língua-gênero são especialmente a dicotomia língua e fala, o conceito de signo enquanto relação entre significante e significado, a questão da arbitrariedade e da relativa motivação do signo e o conceito de valor. Inicio pela dicotomia língua e fala.

\section{Lingua e fala do gênero}

Uma década antes de publicar o trabalho em que lança a teoria semiótica estruturada em bases linguísticas, aí incluídas as de Saussure, Greimas já reconhecia que, devido à sua eficácia, o pensamento saussuriano havia transposto os quadros da linguística e estava sendo retomado e utilizado pela epistemologia geral das ciências humanas (GREIMAS, 2000, p. 372). Para comprovar a amplitude do valor epistemológico das dicotomias saussurianas, Greimas cita justamente um estudo 
baseado nas relações de gênero: o "Structure Sociale", de Claude Lévi-Strauss, publicado em 1953 (GREIMAS, 2000, p. 374).

A dicotomia operada por Lévi-Strauss é justamente a que articula língua e fala. Saussure acreditava que língua deveria ser estudada por ela mesma, e não pelas relações que estabelece com fatores externos. Nesse princípio, a fala é externa e deve ser considerada separadamente. Enquanto a língua é virtualizada e coletiva, estando presente na mente de todos os indivíduos unidos por essa língua, a fala é realizada e individual. Apesar de diferentes, elas são interdependentes, e é a fala que faz evoluir a língua (SAUSSURE, 2012, p. 51).

Todos nós temos um sistema de gênero, ou uma línguagênero, na mente. Somos unidos por essa língua e há um consenso entre nós, seus falantes, das associações que se estabelecem entre um significante ou imagem acústica e entre um significado ou conceito, ou seja, dos signos que formam esta língua.

$\mathrm{Na}$ associação aqui desenvolvida, consideremos que a língua-gênero possui apenas dois significados/conceitos: masculino e feminino. Já os significantes associados a cada significado são inúmeros. "Falar" a língua-gênero é, portanto, realizar e atualizar individualmente esse sistema. Falamos essa língua toda vez que escolhemos roupas, posturas, tons de voz, gestos, profissões, cortes de cabelo, comidas, bebidas, animais de estimação, carros, sentimentos, estilos musicais, formas de lazer.

Em nossos atos de fala, reforçamos as associações já estabelecidas ou propomos novas associações. A "fala" das identidades gênero-divergentes propõe combinações não permitidas pela língua, ou melhor, pela variedade normativa da língua. No entanto, se tais falas forem aceitas e adotadas pela comunidade, poderão deixar a esfera individual da fala e passar a compor a esfera coletiva do sistema.

Considerando que a fala envolve a organização corporal, são os signos-corpo que mais desafiam a ideia da arbitrariedade. No entanto, acredito que esse conceito é bastante produtivo para a compreensão do funcionamento dessa língua-gênero. 


\section{A arbitrariedade e a motivação relativa dos signos de gênero}

Para Saussure (2012, p. 108), “[...] todo meio de expressão aceito numa sociedade repousa em princípio num hábito coletivo ou, o que vem a dar na mesma, na convenção". Ou seja, todo signo é arbitrário. Mais exatamente, "[...] o significante é imotivado, isto é, arbitrário em relação ao significado, com o qual não tem nenhum laço natural na realidade" (SAUSSURE, 2012 , p. 109). Tais princípios podem ser ampliados para o signo de gênero, e neles se confirma a ideia de que o gênero é uma construção, e não algo natural, assim como as normas que governam as relações de seu sistema.

Como já sinalizado anteriormente, nem mesmo os aspectos chamados biológicos, como a genitália ou as partes sexuais, podem ser considerados motivados em relação a gênero. A genitália obviamente é uma realidade, mas o estabelecimento de uma diferenciação dos seres humanos com base neste aspecto e a consequente divisão social daí advinda são procedimentos arbitrários, discursivos. $\mathrm{O}$ que parece ser algo ontológico, pertencente à ordem natural das coisas, é, para Monique Wittig,

[...] uma construção mítica e sofisticada, uma 'formação imaginária' que reinterpreta as características físicas (em si mesmas tão neutras como outras, mas marcadas por um sistema social) por meio da rede de relações em que são percebidas. (WITTIG, 1981 apud BUTLER, 2003, p. 166)

$\mathrm{Ou}$, a mesma lógica nas palavras de Butler, “[...] o 'sexo' impõe uma unidade artificial a um conjunto de atributos de outro modo descontínuos" (BUTLER, 2003, p. 166). Tal divisão dos seres humanos pelo sexo não tem outra razão de existir que a adequação "[...] às necessidades econômicas da heterossexualidade, emprestando um lustro naturalista à sua instituição" (BUTLER, 2003, p. 164).

E, no entanto, talvez esse "lustro naturalista" consiga se sustentar em parte porque, de acordo com Saussure, alguns signos não são absolutamente arbitrários. Nestes “[...] intervém um fenômeno que permite reconhecer graus no arbitrário sem suprimi-lo: o signo pode ser relativamente motivado" (SAUSSURE, 2012, p. 180, grifo do autor). Por questões de produtividade da língua, o espírito "[...] logra introduzir um princípio de ordem 
e de regularidade em certas partes da massa de signos, e esse é o papel do relativamente motivado" (SAUSSURE, 2012, p. 181).

O exemplo de Saussure é dado pela comparação entre os números "vinte" e "dezenove". Se primeiro é imotivado, o segundo já não tanto, pois evoca termos que o compõem, como o "dez" e o "nove" (SAUSSURE, 2012, p. 180). Propondo também um exemplo a título de ilustração, e operando a mesma lógica nos signos de gênero, imaginemos o momento em que houve a divisão arbitrária dos humanos a partir da genitália. Notouse que aqueles corpos enquadrados na classificação "fêmea" apresentavam formas corporais mais arredondadas em comparação às formas corporais mais retilíneas dos humanos classificados como "macho". No processo de imposição da coerência entre sexo, identidade e expressão de gênero (macho/ homem/masculino, fêmea/mulher/feminino), algumas características (mais) presentes no corpo da fêmea podem ter passado a constituir o paradigma do feminino (e o mesmo com o corpo do macho, como as formas fálicas, por exemplo).

No contexto dessa ilustração, o significante "formas curvas" passa a ser associado ao significado "feminino". Assim, a partir de uma arbitrariedade inicial, muitos signos de gênero podem vir a se constituir por associação de motivação relativa. Isso promove tanto a economia (Butler) quanto a produtividade (Saussure) do sistema e faz com que este funcione sozinho, viabilizando o tal "lustro naturalista".

As associações arbitrárias ou motivadas que constituíram os signos de gênero não são um problema em si. Um dos problemas é a imposição de apenas algumas combinações de signos, ou seja, aquelas que compõem identidades prescritas pela norma. $\mathrm{O}$ outro problema é a qualificação negativa de alguns signos e combinações. O princípio saussuriano de valor é bastante útil para clarear esses processos e, pelas discussões que encerra, recebe uma seção própria.

\section{A questão do valor}

$\mathrm{O}$ aspecto da arbitrariedade na conversão de partes do corpo em signos de gênero obedece ao mesmo princípio proposto por Saussure (2012, p. 167) para a língua: “[...] a língua não comporta ideias nem sons preexistentes ao sistema linguístico, mas somente diferenças conceituais e diferenças 
fônicas resultantes desse sistema". Essas diferenças, por sua vez, estão na base do valor linguístico, princípio que igualmente opera no sistema de gênero. Suporta esta ideia o fato de que

[...] é uma grande ilusão considerar um termo simplesmente como a união de certo som com certo conceito. Defini-lo assim seria isolá-lo do sistema do qual faz parte; seria acreditar que é possível começar pelos termos e construir o sistema fazendo a soma deles, quando, pelo contrário, cumpre partir da totalidade solidária para obter, por análise, os elementos que encerra. (SAUSSURE, 2012, p. 160)

Isso implica que a classificação prévia de gênero, ou seja, sem considerar que ela emerge do sistema que está sendo observado/analisado, pode levar a distorções nas análises ou à não percepção de fatores que estão em jogo, como já exemplificado pelo trabalho de Schiebinger (2014). Um exemplo da operação desse princípio, agora bem-sucedido, vem do estudo de Maria Rosa Lombardi (2006) sobre mulheres e engenharia. Num sistema de profissões, a engenharia é masculina em comparação com a nutrição, por exemplo. Mas, no sistema das engenharias, química é mais feminina que mineração. E, na engenharia de mineração, prospectar água é mais feminino do que prospectar petróleo.

O estudo ilustra que, assim como a língua, o gênero é “[...] um sistema em que todos os termos são solidários e o valor de um resulta somente da presença simultânea de outros [...]" (SAUSSURE, 2012, p. 161). Considerando a prática de generificação da nossa cultura, um sistema hipotético constituído apenas pela cor azul - em princípio uma cor "masculina" - teria alguns azuis masculinos e outros femininos. A adoção de apenas um azul eliminaria a diferenciação, o que não atenderia à necessidade da economia heterossexual, como dito por Butler logo antes.

A noção de valor também é útil para tratar da integração no sistema das identidades gênero-divergentes. Sob a regência da gramática normativa de gênero, esse sistema era até então constituído apenas pelas classes "homem" e "mulher". Explicando melhor a associação e resgatando outras já apresentadas: se gênero é uma "língua" na qual opera uma gramática, existe uma gramática normativa que considera erradas as combinações (as sintaxes?) não previstas por essa norma. Das combinações aprovadas e obrigatórias resultam as 
${ }^{5}$ Trata-se do one-sex model, vigente da Antiguidade grega até o século XVIII, oposto ao two-sex model no qual nos baseamos hoje para diferenciar homens e mulheres - ou machos, fêmeas e pessoas intersexo, segundo as categorias adotadas neste trabalho. Este modelo de divisão sexual é uma proposição de Thomas Laqueur, apresentada em 1990 no livro Making Sex: Body and Gender from the Greeks to Freud. Sua descrição foi retomada em muitos trabalhos sobre gênero e sexualidade, dentre os quais o de Jurandir Freire Costa (1996) sobre a identidade homossexual. classes - as identidades de gênero - "homem" e "mulher". Uma gramática descritiva de gênero analisaria o que efetivamente ocorre no sistema - e, certamente, as identidades são muito mais plurais do que apenas essas duas - e explicaria as suas regras de organização. Não para "ensinar", como se faz com a gramática da língua, e sim para apresentar essas combinações não conformes e legitimá-las.

As regras de organização que emergiriam desta perspectiva descritiva da gramática mostrariam que, na realidade, as ideias tradicionais de "homem" e "mulher" estão cada vez mais esvaziadas. E isso pode ser explicado por Saussure (substituindo, é claro, os exemplos linguísticos pelas identidades de gênero):

No interior de uma mesma língua, todas as palavras que exprimem ideias vizinhas se limitam reciprocamente: sinônimos como recear, temer, ter medo só têm valor próprio pela oposição; se recear não existisse, todo seu conteúdo iria para seus concorrentes. (SAUSSURE, 2012, p. 163, grifos do autor)

Muitos dos conteúdos hoje investidos na ideia de mulher já foram apenas do homem, quando a mulher era vista como um homem menor, ou invertido 5 . A partir da concepção da mulher como sujeito independente do homem, consolidada no século XIX, essa classe passou a ter valor (no sentido saussuriano) próprio, ainda que disfórico. As "novas" identidades (novas porque agora começam a ser legitimadas, denominadas, definidas, mas não porque não tivessem sempre existido), na medida em que passam a compor o sistema de gênero, restringem os conteúdos das duas identidades existentes até então e passam a ter valor próprio também.

Note-se que considero a ampliação das classificações, ou seja, das "palavras", mas mantenho as categorias masculino e feminino. Essas novas classificações trabalham com combinações de elementos do masculino e do feminino de maneira diferente do que se entende, em termos normativos, como homem e mulher. O que o senso comum chama pejorativamente de "homem afeminado", por exemplo, na medida em que combina elementos do feminino e do masculino em proporções diferentes do que exige a norma, já constitui uma identidade com valor (saussuriano) próprio. Não trago aqui as classificações, mas é possível encontrar definições em algumas fontes de instituições 
que as adotam como, por exemplo, a Universidade de Berkeley (UNIVERSITY, 2017), e também no "Dicionário Transgênero" que integra o já citado livro de Lanz (2015).

Ainda sobre a questão do valor, entra em cena a diferenciação que Saussure estabelece entre língua e fala: o som da fala é algo secundário, é apenas matéria para colocar a língua em jogo. A matéria fônica - e também a escrita, segundo o exemplo a seguir - só importa na medida em que permite diferenciar uma palavra de outra: "Quer eu escreva as letras em branco ou preto, em baixo ou alto relevo, com uma pena ou com um cinzel, isso não tem importância para a significação" (SAUSSURE, 2012, p. 167). Neste ponto, é necessário rever a proposição de Saussure: os conceitos de gênero, assim como os da língua, também se manifestam na matéria.

Nos desenvolvimentos que fez dos estudos saussurianos, Louis Hjelmslev (1975) desdobra o signo em texto, amplia os conceitos de significante para expressão e o de significado para conteúdo, cada um deles constituído por uma forma e uma substância. Para Hjelmslev, o sentido não está apenas no conteúdo, mas também na expressão, o que vai pavimentar o caminho já parcialmente aberto por Saussure para a operação dos princípios linguísticos em outros sistemas que não os verbais.

Para exemplificar esse processo no sistema de gênero, podemos tomar a matéria fônica mesmo: o tom de voz vai conferir diferentes sentidos e valores à palavra ou à fala ao ser reconhecido como masculino ou feminino. E tomando um outro tipo de matéria: uma roupa é classificada por graus de masculinidade ou feminilidade não apenas por conta de seu conteúdo - saia e calça, por exemplo - mas também da cor, do tecido, da modelagem.

${ }^{6}$ Tradução minha para: "L’immagine di língua di Saussure è austera, e così la sua linguistica della langue, ed è al di fuori della lingua che egli colloca molte delle condizioni di produzione e comprensioni dei testi. Se Saussure avesse potuto sviluppare quella linguistica della parole cui più volte fa riferimento, li avremmo trovato almeno una parte di queste condizioni".

De qualquer forma, as sementes desses desdobramentos mesmos já estavam na linguística saussuriana. Como explica Daniele Gambarara,
A imagem de língua de Saussure é austera assim como sua linguística da língua, e é fora da língua que ele coloca muitas das condições de produção e compreensão dos textos. Se Saussure tivesse tido a oportunidade de desenvolver aquela linguística da língua à qual tantas vezes se refere, teríamos nela encontrado ao menos uma parte destas condições. ${ }^{6}$ (GAMBARARA, 2017, p. 9) 
Para encerrar o tratamento do conceito de valor e as associações de forma geral, um último princípio saussuriano:

Quando se diz que os valores correspondem a conceitos, subentende-se que são puramente diferenciais, definidos não positivamente por seu conteúdo, mas negativamente por suas relações com os outros termos do sistema. Sua característica mais exata é ser o que os outros não são. (SAUSSURE, 2012, p. 164)

Entendo este como um dos mais produtivos princípios linguísticos para os estudos de gênero, na medida em que permite considerar as identidades de gênero no âmbito de um regime que articula diferentes combinações de masculino e feminino, começando pela constatação de que um é aquilo que o outro não é. Esquematicamente, masculino e feminino podem ser distribuídos em oposição nos pontos extremos de um eixo, e depois desdobrados - assim como fez Greimas com esse princípio saussuriano ${ }^{7}$ - em suas contrapartes contraditórias (não-masculino e não-feminino), formando uma grade para entendimento das identidades de gênero a partir da sobredeterminação de cada dupla de termos. Esta grade apresentaria, assim, identidades que afirmam a presença tanto do masculino quanto do feminino; as que negam essas presenças; aquelas constituídas pelo feminino e pelo nãomasculino; e, consequentemente, aquelas constituídas pelo masculino e pelo não-feminino ${ }^{8}$.

Este modelo pode ser especialmente útil quando não for

Em sua História concisa da Semiótica, Anne Hénault observa que "[...] quando, a partir do fim dos anos 1960, A. J. Greimas propõe as primeiras notações de feição algébrica, bem como o primeiro verdadeiro 'modelo' semiológico (o quadrado semiótico), ele se inscreve no exato prolongamento do projeto saussuriano" (HÉNAULT, 2006, p. 49).

8 O detalhamento deste modelo integra uma comunicação proferida em maio de 2017 no Congrès de l'Association Française de Sémiotique. Até o momento, somente o resumo expandido desta comunicação foi publicado (BAGGIO, 2017). desejável definir, catalogar, nomear cada identidade. Este é o caso de algumas vertentes dos estudos transgêneros, como aquela percorrida por Letícia Lanz, que questiona:

Mas será que alguém é capaz de estabelecer, sem arroubos românticos ou explicações da carochinha, quais são as reais e inequívocas fronteiras identitárias entre homem e mulher? $\mathrm{Ou}$ entre travesti, transexual, crossdresser e dragqueen, por exemplo, apenas para citar as quatro identidades transgêneras mais comumente citadas na rede? (LANZ, 2015, p. 367)

Pode-se distribuir as identidades no modelo de acordo com as combinações que assumem ou negam de masculino e feminino. A partir daí, pode-se verificar qual valoração, eufórica ou disfórica, é atribuída a cada uma delas, considerando 
sempre o sistema em que se inserem. Pois é na valoração que residem os problemas, e não na identidade de gênero que cada um assume para si.

\section{Considerações finais}

O objetivo deste artigo foi a proposição de um modelo para os estudos de gênero a partir dos princípios linguísticos de Saussure. Mesmo os primeiros contatos que se tem com sua obra já vêm acompanhados da informação de que esses princípios ultrapassaram a operação na linguística. Para alguns, ajudaram a constituir a própria Linguística como ciência; para outros, inauguraram novos métodos para o tratamento de objetos de outras ciências.

Penso que os princípios de Saussure são bastante pertinentes para os estudos de gênero, mesmo tomados "ao pé da letra", e não apenas nos desdobramentos já mais desenvolvidos em outras ciências, como a semiótica e a sociologia. Procurei mostrar isso com o resgate pontual e até eventualmente didático de alguns pontos. Outros foram deixados de lado, como a relação entre sincronia e diacronia, que é igualmente produtiva para esses estudos. Afinal, gênero é uma construção histórica e esta dicotomia pode ajudar a entender as transformações do sistema com o passar do tempo.

Os exemplos trazidos aqui tiveram a função de "explicar" as associações entre os princípios e o sistema de gênero. Tais exemplos certamente não dão conta de todas as operações. A validade do modelo pode ser testada em situações mais circunscritas e específicas, gerando novos exemplos que contribuam para lhe dar corpo, ou para apontar as suas deficiências.

De qualquer forma, seja com este ou outro modelo, é cada vez mais importante que se considere o viés de gênero na pesquisa científica, e não apenas nas ciências sociais ou humanas. Não sei se alguém ainda postula a objetividade absoluta da ciência. Assumindo que ela se constrói também a partir da subjetividade dos pesquisadores, das instituições e dos órgãos de fomento, esse é um viés que não pode ser deixado de lado. E como a pesquisa é manifestada, apresentada e distribuída por meio da língua - algo que todo pesquisador obrigatoriamente domina -, talvez uma grade de leitura de 
gênero estruturada por princípios linguísticos tenha um acesso mais amplo e transversal.

\section{REFERÊNCIAS}

BAGGIO, A. T. Proposition d'un modèle sémiotique pour les études de genre. In: CONGRÈS DE L'ASSOCIATION FRANÇAISE DE SÉMIOTIQUE, 2017, Paris. Greimas aujourd'hui: l'avenir de la structure. Livre des résumés. Paris: AFS, 2017, p. 114-115.

BOUQUET, S. De um pseudo-saussure aos textos saussurianos originais. Tradução Roberto Leiser Baronas e Vanice Maria de Oliveira Sargentini. Revista Letras \& Letras, Uberlândia, v. 1, p. 161-175, jan./jun. 2009. Disponível em: <http://www.seer.ufu. br/index.php/letraseletras/article/view/25475>. Acesso em: 31 ago. 2017.

BUTLER, J. Problemas de gênero: feminismo e subversão da identidade. Tradução Renato Aguiar. Rio de Janeiro: Civilização Brasileira, 2003.

CONNELL, R. La organización social de la masculinidad. In: VALDÉS, Teresa; OLAVARRÍA, José (Org.). Masculinidad/ es: poder y crisis. Santiago: Isis/Flacso, 1997, p. 31-48.

COSTA, J. F. O referente da identidade homossexual. In: PARKER, R.; BARBOSA, R. M. (Org.). Sexualidades brasileiras. Rio de Janeiro: Relume-Dumará, 1996, p. 63-89.

FIORIN, J. L.; FLORES, V. do N.; BARBISAN, L. B. Por que ainda ler Saussure? In: (Org.). Saussure: a invenção da linguística. São Paulo: Contexto, 2013, p. 7-20.

FRANCHI, C. Mas o que é mesmo "gramática"? In: FRANCHI, C.; NEGRÃO, E. V.; MÜLLER, A. J. Mas o que émesmo "gramática"?. São Paulo: Parábola Editorial, 2006, p. 11-33.

GAMBARARA, D. La semiotica di Saussure e la semiotica di Hjelmslev. In: ZINNA, A.; CIGANA, L. (Ed.). Louis Hjelmslev (1988-1965). Le forme del linguaggio e del pensiero. Toulouse: Éditions CAMS/O, Collections Actes, 2017. Disponível em: $<$ http://mediationsemiotiques.com/cu_01>. Acesso em: 31 ago. 2017. 
GÊNERO. In: DICIONÁRIO Priberam da Língua Portuguesa. Lisboa: Priberam Informática, 2013. Disponível em: <https://www.priberam.pt/dlpo/g\%C3\%AAnero>. Acesso em: 31 ago. 2017.

GREIMAS, A. J. L'actualité du saussurisme (1956). In: La mode en 1830. Langage et société: écrits de jeunesse. Préface de Michel Arrivé. Textes établis par Thomas F. Broden et Françoise Ravaux-Kirkpatrick. Paris: PUF, 2000, p. 371-382.

HÉNAULT, A. História concisa da Semiótica. Tradução Marcos Marcionilo. São Paulo: Parábola, 2006.

HJELMSLEV, L. Prolegômenos a uma teoria da linguagem. São Paulo: Perspectiva, 1975.

HOBSBAWM, E. J. Nações e nacionalismo desde 1780: programa, mito e realidade. Tradução Maria Celia Paoli e Anna Maria Quirino. Rio de Janeiro: Paz e Terra, 1990.

LAQUEUR, T.W. Making Sex: Body and Gender from the Greeks to Freud. Harvard University Press, 1990.

LANZ, L. O corpo da roupa: a pessoa transgênera entre a transgressão e a conformidade com as normas de gênero. Uma introdução aos estudos transgêneros. Curitiba: Transgente, 2015.

LOMBARDI, M. R. Engenheiras brasileiras: inserção e limites de gênero no campo profissional. Caderno de Pesquisa, v. 36, n. 127, p. 173-202, jan./abr. 2006. Disponível em: <http:// www.scielo.br/scielo.php?script $=$ sci_arttext\&pid=S0100$15742006000100008 \& \operatorname{lng}=\mathrm{en} \& \mathrm{nrm}=\mathrm{iso} \& \mathrm{t} \operatorname{lng}=\mathrm{pt}>$. Acesso em: 31 ago. 2017.

MATHIEU, N-C. Sexo e gênero [verbete]. Tradução Naira Pinheiro. In: HIRATA, H.; LABORIE, F.; LE DOARÉ, H.; SENOTIER, D. (Org.). Dicionário crítico do feminismo. São Paulo: Editora Unesp, 2009.

MATOS, M. I. S. de. Gênero: categoria/perspectivas e constituição do campo historiográfico. In: TAMANINI, M.; BOSCHILIA, R.; SCHWENDLER, S.F. (Org.). Teorias e politicas de gênero na contemporaneidade. Curitiba: Editora da UFPR, 2017, p. 39-63. 
SAUSSURE, F. de. Curso de linguística geral. Organizado por Charles Bally e Albert Sechehaye. Prefácio à edição brasileira de Isaac Nicolau Salum. Tradução de Antônio Chelini, José Paulo Paes e Izidoro Blikstein. 28. ed. São Paulo: Cultrix, 2012.

SCHIEBINGER, L. Expandindo o kit de ferramentas agnotológicas: métodos de análise de sexo e gênero. Revista Feminismos, Salvador, v. 2, n. 3, p. 85-103, set./dez. 2014. Disponível em: <http://www.feminismos.neim.ufba.br/index. php/revista/article/view/125>. Acesso em: 31 ago. 2017.

TRABANT, J. Faut-il défendre Saussure contre ses amateurs? Notes item sur l'étymologie saussurienne. In: CHISS, J-L.; DESSONS, G. Langages. Larousse, Paris, n. 159, sep. 2005. apud FIORIN, J. L.; FLORES, V. do N.; BARBISAN, L. B. Por que ainda ler Saussure? In: . (Org.). Saussure: a invenção da linguística. São Paulo: Contexto, 2013.

UNIVERSITY OF CALIFORNIA, BERKELEY. Centers for Educational Justice \& Community Engagement. Definition of Terms. Berkeley, 2017. Disponível em: <http://ejce.berkeley.edu/ geneq/resources/lgbtq-resources/definition-terms $>$. Acesso em: 31 ago. 2017.

WITTIG, M. One is Not Born a Woman. Feminist Issues, v. 1, n. 2, winter 1981 apud BUTLER, J. Problemas de gênero: feminismo e subversão da identidade. Tradução Renato Aguiar. Rio de Janeiro: Civilização Brasileira, 2003. 


\section{Abstract \\ A proposal of operation of Saussure's linguistic principles in gender studies}

This paper proposes a model for gender studies based on F. de Saussure's linguistic principles. It is assumed that the relations Saussure established between the language (langue) system and other semiological systems, as the gender one, authorize the projection of principles from the former system to the latter. The model concentrates on concepts of language (langue) and speech, signified and signifier, arbitrary and relatively motivated signs, and value. The work seeks to show that the notion of language as a system of relations - of signs as something motivated and of value as constituent of identity - is aligned with the conception of gender as a construction and as a discourse. This approach refuses the idea of a natural origin of gender rules and classifications, as well as Saussure rejects the same for language. In order to deal with the rules that organize gender relations, the concepts of normative grammar and descriptive grammar of the language are projected into it. While the first one determines and imposes relations and identities on the basis of a compulsory heterosexual matrix, the second can fulfill the role of unveiling what actually emerges from the system. In this sense, the research aims to show that the model can be productive to contemplate gender-divergent identities in cases where it is preferable to avoid approaching the denominations and classifications of these identities. It is also suggested that the model may be especially useful for the adoption of a gender bias in scientific research, since its linguistic base facilitates transversality in different areas.

Keywords: Saussure. Gender studies. Gender grammar. Language and speech. Value theory. 